\title{
Não Neutralidade da Ciência-Tecnologia: verbalizações necessárias para potencializar a constituição de uma cultura de participação
}

DOI 10.26512/Ic.v24i0.19701

\author{
Suiane Ewerling da Rosa \\ Universidade Federal do Oeste da Bahia/Ensino de Física \\ suiane.rosa@ufob.edu.br \\ Roseline Beatriz Strieder \\ Universidade de Brasília/Instituto Física \\ roseline@unb.br
}

\section{Resumo}

Neste artigo defendemos que o endosso à concepção de neutralidade da ciência-tecnologia (CT) pode fragilizar a participação da sociedade em processos decisórios sobre temas e problemas reais condicionados pelo desenvolvimento científico-tecnológico. Neste sentido, consideramos importante a verbalização de silenciamentos associados à suposta neutralidade da CT e que envolvem reflexões sobre:à origem, concepçãoe direcionamento da CT; os conhecimentos mobilizados para a resolução de problemas sociais; e, questões valorativas internalizadas na CT. Diante disso, além de uma discussão sobre a suposta neutralidade da CT, sua relação com o movimento e a educação CTS, apresentamos, por meio da análise da produção da área de ensino de ciências, sinalizações de verbalização desses silenciamentos. Dessas reflexões, destacamos perspectivas e desafios atrelados à verbalização dos silenciamentos e a necessidade de investigações centradas nas potencialidades de práticas educativas para a superação da concepção de neutralidade da CT. Perspectivas essas, no nosso entender, fundamentais para a constituição de uma cultura de participação.

Palavras-chave: Ciência-Tecnologia-Sociedade, Educação Científica, Neutralidade da Ciência. 


\section{Abstract}

The understading of the neutrality of science-technology activity may undermine the participation of society in decision-making processes about scientific and technological issues. In this way, we have considered important the verbalisation of silencings associated with the supposed neutrality of the science-technology activity. This silencings involve reflections based on: the origin, conception and direction of the science-technology activity; the knowledge which is mobilized for solving social problems; and, the values internalized in the science-technology activity. In addition to that discussion, we present, through the analysis of the production of the Brazilian area of science-technology-society education, signs of verbalization of these silencings. From these reflections, we highlight perspectives and challenges related to the verbalization of the silencings. Furthermore we highlight the requirements for investigations on focusing the potentialities of educational practices to overcome the conception of science-technology neutrality. These perspectives, in our opinion, are fundamentals to the constitution of a participation culture.

Keywords: Science-Technology-Society, Science Education, Neutrality of Science

\section{Resumen}

La comprensión de ciência y tecnología neutras puede fragilizar la participación de la sociedad en los procesos de toma de decisiones sobre cuestiones científicotecnológicas. De esta manera, entendemos qué és importante la verbalización de silenciamientos asociados con la supuesta neutralidad de la actividad científicotecnológica. Estos silenciamientos implican reflexiones basadas en: el origen, la concepción y la dirección de la actividad científico-tecnológica; el conocimiento que se moviliza para resolver problemas sociales; $y$, los valores internalizados en la actividad científico-tecnológica. Además de esa discusión, presentamos, a través del análisis de la producción del área de educación ciencia-tecnología-sociedad en Brasil, propuestas para verbalizar estos silenciamientos. A partir de estas reflexiones, destacamos possibilidades y desafíos relacionados con la verbalización de los silenciamientos. Además, destacamos la necessiudad de investigaciones centradas en estudios de aula que busquen la superación de la concepción de neutralidad científico-tecnológica. Estas perspectivas, en nuestra opinión, son fundamentales para la constitución de una cultura de participación.

Palabras-clave: ciencia-tecnología-sociedad, enseñanza de ciências experimentales, neutralidad de la ciência. 


\section{Résumé}

La compreension de la neutralité de l'activité scientifique et technologique peut nuire à la participation de la société aux processus de prise de décision concernant les questions scientifiques et technologiques. De cette manière, nous avons considéré important la verbalisation des silencieux associés à la neutralité supposée de l'activité scientifique et technologique. Ces silencieux impliquent des réflexions basées sur: l'origine, la conception et la direction de l'activité scientifique et technologique; le savoir mobilisé pour résoudre les problèmes sociaux; et, les valeurs internalisées dans l'activité scientifique et technologique. En plus de cette discussion, nous présentons, à traversd'analyse dela production du secteur brésilien d'éducation science-technologiesociété, des signalisations de verbalisation de ces silencieux. Par conséquent, nous mettons en évidence les perspectives et les défis liés à la verbalisation des silencieux. En outre, nous soulignons les exigences pour la recherche sur la focalisation des potentialités des pratiques éducatives pour surmonter la conception de la neutralité de la science et de la technologie. Ces perspectives, à notre avis, sont fondamentales pour la constitution d'une culture de participation.

Mots clés: science-technologie-société, enseignement de la science expérimentale, neutralité de la science.

\section{Reflexos, importância e sinalizações de um campo polissêmico}

O sistema educacional, em especial no ensino de ciências, vivencia diferentes problemas em seu contexto. Esses problemas vão desde altos índices de evasão escolar, repetência até práticas desmotivadoras e desinteresse atribuído pelo estudante ao que se faz na escola. Assim, a necessidade por mudanças significativas é pauta de diferentes estudos e discussões da área educacional, o que perpassa por repensar o papel, objetivos, estrutura curricular, entre outros, da escola e do ensino de ciências. Visando isso e compreendendo que a formação almejada é aquela que busca a constituição de cidadãos críticos, conscientes e atuantes em uma sociedade marcada pelo contexto técnico-científico, entendemos como importante repensar as práticas educativas e articulá-las à educação ciência-tecnologia-sociedade (CTS).

A educação CTS, no ensino de ciências, é caracterizada por uma diversidade de abordagens. Aikenhead (2003) expõe que apesar dessa multiplicidade de trabalhos, eles coincidem, de um modo geral, por enfatizar práticas associadas à reformulação do ensino de ciências e por valorizar características humanísticas. $O$ autor declara 
que, como cada país possui uma realidade social própria, as relações entre ciência e sociedade também devem assumir papeis contextuais. Na mesma linha, Santos (2011) em uma análise dos diferentes slogans da educação CTS destaca que eles incorporaram o movimento de educação científica visando à formação para a cidadania. Para o autor, os diferentes significados para o que tem sido chamado de CTS, estão associados ao fato de muitos pesquisadores, com distintas preocupações, terem adotado esse enfoque e o adequado as suas demandas.

Ou seja, como propõe Strieder (2012), o significado atribuído à CTS não pode ficar restrito a uma única definição. Para a autora essa diversidade não está, necessariamente, associada à compreensão sobre CTS dos pesquisadores, mas, principalmente, aos espaços pedagógicos nos quais as práticas são desenvolvidas. Além disso, a autora destaca que um elemento central das propostas CTS diz respeito à participação social, que esta comparece sob diferentes perspectivas, que vão desde o acesso à informação até à reivindicação de participação no âmbito das políticas de ciência-tecnologia (CT).

Diante deste cenário, dentre as diferentes abordagens possíveis, destacamos a de Auler (2011) que traz como objetivo central desse movimento a busca por uma maior participação da sociedade em processos decisórios sobre temas e problemas reais condicionados pelo desenvolvimento da CT. É válido ressaltar que os processos participativos, democráticos, podem ser fragilizados pelo endosso à concepção de neutralidade da CT (Rosa \& Auler, 2016). Como discutem Rosa e Auler (2016), "(...) uma compreensão ampla sobre não neutralidade da CT, o que inclui a presença de valores em sua gênese (agenda de pesquisa), constitui elemento chave para uma práxis ampliada de participação em processos decisórios" (p. 206).

Neste sentido, seguindo os autores supracitados, consideramos importante a verbalização de silenciamentos associados à suposta neutralidade da CT, em específico: à origem, concepção e direcionamento da $\mathrm{CT}$; aos conhecimentos mobilizados para a resolução de problemas sociais; e, as questões valorativas internalizadas na CT. Esses silenciamentos são, portanto, omissões de concepções relacionadas à suposta neutralidade da CT. Omissões que caso permaneçam silenciadas reforçam posturas passivas diante das decisões referentes a temas científico-tecnológicos.

Assim, dando continuidade aos trabalhos desenvolvidos por Rosa (2014) e Rosa e Auler (2016), o objetivo deste artigo centra-se em aprofundar as reflexões sobre a não neutralidade da CT, em especial, sobre a verbalização dos silenciamentos associados a ela no âmbito da Educação Científica CTS. A matriz teórica adotada neste estudo está pautada nos pressupostos de Paulo Freire, referenciais do movimento CTS e do Pensamento Latino-Americano em Ciência-Tecnologia-Sociedade (PLACTS), nos quais a potencialização de uma cultura de participação constitui-se um pressuposto central. Além de uma discussão sobre a suposta neutralidade da CT e sua relação com a origem do movimento e da educação CTS, apresentamos os silenciamentos e, por 
meio da análise da produção da área de ensino de ciências, sinalizações de verbalização desses silenciamentos. Esperamos, com isso, contribuir para uma maior clareza em torno dos elementos centrais da educação CTS, além de apontar perspectivas para sua implementação em sala de aula.

\section{Marcos do surgimento do movimento CTS}

Marcando o início do surgimento do movimento CTS, no final dos anos cinquenta, pós Segunda Guerra Mundial, houve uma crescente percepção de que o desenvolvimento científico-tecnológico não estava conduzindo linear e automaticamente ao bem-estar da sociedade (García, Cerezo \& López, 1996). Questionar as implicações e produção do desenvolvimento científico-tecnológico é ter como pano de fundo, críticas a algumas dimensões centradas na concepção da suposta neutralidade da CT. Segundo os autores, dentre as publicações que têm sido consideradas como marco inicial dessas discussões, estão "A Estrutura das Revoluções Científicas", do historiador da ciência e físico Thomas Kuhn (1962), e "Primavera Silenciosa", da bióloga naturalista Rachel Carson (1962), ambas potencializaram, de alguma maneira, discussões referentes às interações entre ciência, tecnologia e sociedade.

Neste texto destacamos problematizações referentes à publicação apresentada por Carson em "Primavera Silenciosa" já que as denúncias trazidas pela ativista apresentam aspectos comuns com a proposta deste trabalho, em concreto, com a verbalização de concepções pouco críticas sobre CT e que estão relacionadas, por exemplo, à perspectiva da participação social.

O livro "Primavera Silenciosa", publicado nos Estados Unidos em 1962 e, no Brasil, em 1964 marca, pela primeira vez, um alerta mundial referente aos efeitos nocivos do uso de agrotóxicos, bem como a relação existente entre CT e implicações socioambientais. O interesse de Carson pelo tema de investigação inicia-se em 1945, quando biólogos dos Estados Unidos começam a estudar os efeitos nocivos provocados no ambiente pelo uso do DDT (dicloro-difenil-tricloroetano).

Segundo Pereira (2012), o DDT foi sintetizado pela primeira vez em 1874, na Alemanha. Porém, suas propriedades inseticidas foram verificadas apenas em 1939 pelo químico Paul Hermann Müller, que, em 1948, recebeu o prêmio Nobel de Medicina. Esse resultado foi apontado como um dos feitos mais revolucionários até então, já que apresentava sucesso no combate a insetos transmissores de doenças como malária e febre amarela. O uso do DDT disseminou-se após a Segunda Guerra Mundial nas culturas agrícolas, já que possibilitava resultados positivos ao combate de insetos nas produções. Linda Lear, escritora da introdução da edição do livro de 2010, destaca que 
a obra de Carson surge em um período no qual a perspectiva salvacionista da ciência era predominante, uma vez que,

A indústria química, uma das principais beneficiárias da tecnologia do pós-guerra, era também uma das principais autoras responsáveis pela prosperidade nacional norteamericana. [...] A população atribuía aos químicos, trabalhando em seus aventais brancos engomados em remotos laboratórios, uma sabedoria quase divina. Os resultados de seu trabalho eram ornamentados com a presunção de beneficência. Nos Estados Unidos do pós-guerra, a ciência era Deus, e a ciência era masculina (Linda Lear apud Carson, 2010, p.12).

No entanto, bastou pouco mais de uma década pós Segunda Guerra Mundial para que começassem as revelações referentes às contaminações do solo, da água e de morte de animais. Logo, juntando isso e mais as consequências pós-guerra, passou-se a questionar se a ciência seria tão redentora.

O estudo e publicação da obra "Primavera Silenciosa" estiveram relacionados a uma carta de uma amiga que contava sobre a morte de pássaros em seu quintal, após pulverizações aéreas do DDT. De acordo com Pereira (2012), sabendo da urgência e perigo do uso do inseticida, Carson tomou algumas precauções antes de realizar suas denúncias, já que possivelmente traria reações negativas dos produtores dos inseticidas. Com ajuda de colaboradores, ela pesquisou durante quatro anos, revelando, em 1962, que o uso do DDT não matava apenas as pragas das plantações agrícolas ("objetivo" do seu uso), mas também outras espécies, refletindo em todo o ecossistema (solo, água, fauna e flora) e, consequentemente, nos humanos, já que impactava a cadeia alimentar. O título da obra, relacionado às constatações de mortes e problemas nas reproduções dos pássaros devido ao uso do DDT, refere-se ao que Carson queria evitar: "uma estação sem pássaros" (Pereira, 2012), ou seja, uma primavera silenciosa. A publicação do livro resultou em impactos imediatos, tanto de apoio à pesquisadora quanto de repúdio. Cientistas comprometidos com o desenvolvimento de agrotóxicos a atacaram publicamente, primeiramente por não ter o título de doutora, questionando assim a legitimidade do livro, mas também com argumentos preconceituosos pelo fato de ser mulher. Apesar da luta e denúncias de Carson, ela não presenciou os impactos concretos do seu trabalho, já que morreu devido a um câncer em 1964. Embora alguns países tenham banido o DDT a partir do final da década de 1960, no Brasil a fabricação, importação, exportação e comercialização foram proibidas apenas em 2009.

Pereira (2012) ainda cita que, para Carson, a humanidade estaria trilhando um risco produzido por ela mesma. A autora ressalta que, em nome do progresso científico, o uso dos agrotóxicos era visto como necessário, pois seria a maneira de acabar com as pragas na agricultura, conduzindo, assim, a soluções dos problemas relacionados à fome mundial. Esse argumento ainda é muito comum na sociedade e está alicerçado no modelo linear de progresso, no qual o desenvolvimento científico gera desenvolvimento tecnológico, este por sua vez gera o desenvolvimento econômico, 
que por fim irá gerar um desenvolvimento social, sendo que, nessa perspectiva de desenvolvimento, somente decisões tecnocráticas são aceitáveis (García, Cerezo \& López, 1996). Além disso, essa perspectiva associa-se às visões de ciência e tecnologia neutras e redentoras dos problemas da humanidade.

As denúncias de Carson promoveram, naquele momento e contexto, uma "reviravolta" naquela atividade científico-tecnológica e podem ser associadas à verbalização de silenciamentos, em especial, das omissões relacionadas ao modelo linear de desenvolvimento científico-tecnológico.

É a partir deste cenário, que surge, segundo Auler (2002), o movimento CTS, que está associado ao questionamento do modelo de gestão tecnocrática e seus valores "ditos" neutros. De acordo com García, Cerezo e López (1996), o movimento CTS, emergente em meados do século XX, está associado à insatisfação com relação à imagem tradicional da $\mathrm{CT}$, aos problemas políticos, ambientais e econômicos oriundos do desenvolvimento científico-tecnológico. Complementando essa ideia, segundo esses autores, um dos objetivos desse movimento é reivindicar um redirecionamento tecnológico. Ou seja, problematizar o modelo linear de progresso já explicitado.

\section{Vertentes do campo CTS e sua repercussão na Educação}

Diante dos descontentamentos em relação a diferentes problemas relacionados ao desenvolvimento da $\mathrm{CT}$, como, por exemplo, às denúncias de Carson e consequências pós-guerra, García, Cerezo e López (1996), destacam duas principais vertentes que deram origem ao movimento CTS: a europeia e a norte-americana. Essas vertentes objetivavam analisar criticamente a relação entre a tríade CTS e opor-se, principalmente, à visão de ciência autônoma e tecnologia como ciência aplicada, contribuindo desta maneira para a desmistificação da imagem tradicional intelectualista da CT.

Assim, na década de 1960 e 1970, surge na Europa uma resposta mais acadêmica do que social frente aos problemas envolvendo a CT, dando origem aos Estudos da Ciência e da Tecnologia (Cerezo, 1998). Essa tradição enfatizava a dimensão social antecedente ao desenvolvimento científico-tecnológico, centrando-se em descrever como a gênese e aceitação das teorias científicas são influenciadas pela diversidade de fatores econômicos, políticos, culturais, entre outros. Neste sentido, essa vertente preocupa-se em explicar a origem das teorias científicas, tendo a ciência como processo (García, Cerezo \& López, 1996).

De outra maneira, nos Estados Unidos, a corrente CTS é fortemente marcada por uma tradição ativista, preocupada com as consequências socioambientais dos produtos 
tecnológicos, implicada nos movimentos de protestos sociais (Cerezo, 1998). Ao contrário da tradição europeia, a americana tem um caráter mais prático e um alcance valorativo, implicando em uma reflexão ética e educativa, e, no interesse da democratização dos processos de tomada de decisão nas políticas tecnológicas e ambientais (García, Cerezo \& López, 1996).

Há ainda uma terceira tradição, negligenciada na literatura internacional, que é o Pensamento Latino Americano em Ciência-Tecnologia-Sociedade (PLACTS). O PLACTS consistiu de uma reflexão realizada em setores da própria comunidade científica, a qual buscava um redirecionamento para o desenvolvimento científico-tecnológico. Essa vertente emerge também em meados da década de 1960 a partir de dois fenômenos paralelos (Dias, 2008). O autor, citando Cutcliffe (2003), destaca que o primeiro fenômeno está relacionado aos movimentos sociais diante de manifestações por direitos civis e pelo meio ambiente, crítica ao consumismo exacerbado, preocupações relacionadas à pesquisa genética, utilização da energia nuclear, entre outros. $\mathrm{O}$ segundo está associado ao descontentamento de parte da comunidade científica dos países latino-americanos, "frente às recomendações de política pregadas pelos organismos internacionais" (p. 02), como, por exemplo, a Organização das Nações Unidas para a Educação, a Ciência e a Cultura (UNESCO), o Banco Interamericano de Desenvolvimento (BID) e pela Organização dos Estados Americanos (OEA), que apresentavam recomendações relacionadas à visão linear entre CT e desenvolvimento.

A CT desejada pelos seguidores do PLACTS estava na busca por uma agenda de pesquisa que contemplasse as demandas locais/regionais, fazendo da CT "um objeto de estudo público, um tópico ligado a estratégias de desenvolvimento social e econômico" (Von Linsingen, 2007, p. 7). Assim, segundo Dagnino (2010a), o PLACTS constituiu-se numa orientação de um novo tipo de relação entre a tríade CTS. Dessa maneira, essa vertente, que se insere no movimento CTS, discute a necessidade de um redimensionamento da política científico-tecnológica (PCT) no contexto dos países da América Latina.

Já a repercussão do movimento CTS no âmbito educacional, segundo Aikenhead (2003), aconteceu em meados da década de setenta e início de oitenta quando educadores de ciências sentiram a necessidade de mudanças na área, diante da busca de uma educação política, ou seja, passaram a almejar práticas que efetivassem abordagens multidisciplinares, com currículos em torno de problemas reais, visando à democratização de processos decisórios.

No Brasil, em linhas gerais, o movimento CTS repercutiu, de forma pontual, nos currículos de ciências no final da década de 1980, quando se iniciou a reivindicação por uma educação científica visando compreender o uso da tecnologia e consolidar processos democráticos (Strieder, 2008). No entanto, diferentemente ao que ocorreu nos EUA e na Europa, com relação aos referenciais que discutem CTS, o PLACTS não repercutiu no contexto educacional brasileiro, permanecendo no âmbito da própria 
comunidade científica. Assim, essa aproximação vem sendo construída por alguns Grupos de Pesquisa ligados à Educação CTS, bem como em pesquisas pontuais, a exemplo das realizadas por Strieder (2012), Santos (2012), Rosa (2014), Roso (2014), Gall Centa e Muenchen (2016) e Santos (2016).

Diante das discussões realizadas e visando o objetivo deste trabalho, iremos, no próximo item, apresentar alguns elementos referentes a não neutralidade da CT, algo, no nosso entender, fundamental para construções mais críticas sobre CTS. Como ponto de partida, levamos em consideração estudos já realizados em trabalhos anteriores (Rosa, 2014; Rosa \& Auler, 2016).

\section{A não neutralidade da ciência-tecnologia: afinal do que estamos falando?}

As discussões envolvendo dimensões da suposta neutralidade da CT, apesar de serem frágeis na Educação CTS (Santos, 2012; Rosa, 2014; Santos, 2016; Rosa \& Auler, 2016), e consideradas superadas na reflexão epistemológica e sociológica contemporânea, são de extrema relevância, já que a suposta neutralidade persiste em muitos contextos da sociedade (Rosa \& Auler, 2016). Permanecer com esse "mito", segundo Japiassu (1975), pode contribuir para o estado de passividade da sociedade, incluindo os cientistas. Assim, a sociedade que alimenta essa compreensão contribui para a falta de percepção crítica das interações entre ciência-tecnologia-sociedade, comprometendo o processo de constituição de uma cultura científica crítica e de participação das decisões envolvendo CT. A suposta neutralidade é entendida como legitimadora de modelos de decisões tecnocráticas, ou seja, seu endosso pode fragilizar processos participativos, centrais na essência do movimento CTS (Rosa \& Auler, 2016).

Uma das percepções mais questionadas referente à suposta neutralidade da CT é aquela relacionada às dimensões valorativas. No entanto, identificar de forma pouco crítica a relação entre $\mathrm{CT}$ e valores, pouco contribui para a construção de uma ideia problematizadora e significativa. Assim, devido ao discurso genérico de que ciência e tecnologia não são neutras, faz-se necessário compreender e aprofundar suas facetas, articulando as discussões ao defendido no âmbito do movimento CTS.

Conforme apontado por Oliveira (2003), quando estamos falando sobre fenômenos elétricos, sabemos o que significa ser um corpo neutro. Também, na química, uma substância é neutra quando não é ácida e nem alcalina. Porém, o que queremos dizer quando afirmamos que a ciência não é neutra? Para responder a essa pergunta, na sequência, apresentamos reflexões fundamentadas em diferentes pressupostos teóricos. Destacamos que há um universo de possibilidades, porém nos centramos 
nas discussões que, a nosso ver, contribuem para uma compreensão mais próxima do que é defendido pela educação CTS.

Auler (2002), ao discutir a suposta neutralidade da CT, identifica quatro dimensões interdependentes: (i) O direcionamento dado à atividade científico-tecnológica (processo) resulta de decisões políticas; (ii) A apropriação do conhecimento científicotecnológico (produto) resulta de decisões políticas; (iii) O conhecimento científico produzido (produto) não é resultado apenas dos tradicionais fatores epistêmicos: lógica + experiência; e, (iv) O aparato ou produto tecnológico incorpora, materializa interesses, desejos de sociedade ou de grupos sociais hegemônicos.

Neste trabalho, destacamos a importância de articular essas dimensões e suas relações com outros estudos que questionam e refletem sobre neutralidade da CT, ou seja, para a superação da suposta neutralidade da CT, é fundamental problematizarmos essas quatro dimensões de forma articulada.

Analisando-as, defendemos que compreender somente a dimensão "ii", ou seja, que a apropriação do conhecimento resulta de decisões políticas, representa uma percepção pouco crítica sobre a não neutralidade, isso porque, apesar de questionar a apropriação desigual da CT, a criticidade está centrada apenas nos processos pósprodução. Essa perspectiva aproxima-se também da visão instrumental de Dagnino (2010b), ou seja, do bom e mau uso da CT, o qual afirma que cabe à sociedade usar a ética para dar a este bom uso. Assim, "a comunidade de pesquisa produz a CT, cabendo à 'sociedade' fazer o que quiser" (p. 309), ou seja, "a ética entra como uma solução de um problema que não diz respeito aos cientistas" (p. 309). Ainda, se o problema da desigualdade dos alimentos produzidos/consumidos pela população for solucionado por uma apropriação mais igualitária, estaremos satisfeitos sem discutir, por exemplo, a qualidade dessa produção? É nesse sentido que problematizar a dimensão "i" é de extrema importância, pois ela permite analisar como são direcionadas as atividades científicas, ou seja, quais critérios, valores e interesses orientam a atividade científicotecnológica? Considerando que há decisões políticas e externas ao domínio da ciência, é importante questionar a apropriação do conhecimento científico-tecnológico (dimensão "ii"), no entanto, tal conhecimento incorpora questões valorativas já no seu direcionamento (dimensão "i").

Corroborando com essas discussões, a terceira dimensão de Auler afirma que o conhecimento científico produzido (produto) não é resultado apenas dos tradicionais fatores epistêmicos (lógica + experiência), perspectiva que entra em convergência com as discussões de Oliveira (2008), o qual destaca que os valores sociais, morais e pessoais, por exemplo, podem estar presentes no desenvolvimento científicotecnológico. Oliveira (2008) propõe, pelo menos, três domínios distintos associados ao processo de produção do conhecimento, que correspondem a "subteses" da tese da suposta neutralidade: (1) momento da escolha dos fenômenos que serão investigados; (2) definição das teorias propostas que servirão para explicar os fenômenos ou para 
resolver os problemas; e, (3) domínio do conteúdo das proposições científicas.

As ideias propostas nas subteses de Oliveira também são discutidas nas obras de Lacey (2010), a partir da relação entre ciência e valores. O autor defende que a suposição da "ciência livre de valores" constitui construção histórica fundamentada nas teses da: imparcialidade, neutralidade e autonomia. Com a distinção feita pelo autor entre valores cognitivos (adequação empírica, poder explicativo, fecundidade das teorias, certeza, consistência) e outros valores (morais, sociais, etc.), a escolha entre teorias rivais na prática científica, de acordo com a imparcialidade, depende apenas do papel dado às razões epistêmicas e cognitivas, problematização possível com a terceira dimensão de Auler (2002). Segundo Lacey (2010), a ideia da imparcialidade exclui o papel dos valores sociais apenas na escolha entre teorias, ou seja, não são critérios a serem utilizadas na aceitação ou recusa de uma teoria. No entanto, por mais que a teoria atenda aos critérios da imparcialidade, não atenderá necessariamente ao da neutralidade.

Para Lacey, a neutralidade cognitiva implica que não há juízos de valores sociais particulares nas teorias científicas. E, a neutralidade é fundamentada na ideia de que quando aplicadas, as teorias devem informar equitativamente um amplo domínio de valores. Desse modo, não podem privilegiar apenas uma perspectiva valorativa. A ciência, nesse sentido, não pode estar a serviço de valores e interesses particulares. Para o autor, a imparcialidade, apesar de não ser respeitada em muitas práticas científicas, constitui-se um valor central. Já a neutralidade é questionável tanto no que se refere a sua manifestação nas práticas de pesquisa, quanto em possíveis avanços comprometidos com ela.

A autonomia para Lacey não é realizável, pois a mesma representa o guia para alcançar os objetivos e requisitos da imparcialidade e neutralidade. E ainda, as práticas científicas devem ser realizadas em comunidades autônomas, financiadas por instituições autônomas, nas quais não haja interesses e influências externas. Oliveira (2008) também ressalta a ideia de autonomia na prática científica, o qual entende que nessa não pode haver "[...] interferências externas, de natureza religiosa, política ou ideológica" (p. 109). A ciência, nesta perspectiva, está isenta de contaminações valorativas (social, ética, ambiental, política, cultural, étnica, etc.), ou seja, como se as influências externas à prática científico-tecnológica não conseguissem ultrapassar as barreiras postas ao desenvolvimento da CT.

Outro autor cujas reflexões têm contribuído para problematizar a não neutralidade é Dagnino (2008), que em seus estudos sociais sobre CT destaca duas facetas sobre a suposta neutralidade da CT, voltadas para: (a) a CT, e (b) a sociedade. O olhar apenas para a CT possui duas variantes: a neutralidade e o determinismo tecnológico. A primeira carrega consigo a ideia de que a CT não se relaciona com o contexto no qual é gerada, e, permanecer dele sempre isolada é um objetivo e regra de 'boa ciência'. Já o determinismo tecnológico é entendido como se o desenvolvimento socioeconômico 
fosse determinado linearmente pelo avanço da $\mathrm{CT}$, sendo a tecnologia condutora e determinante da estrutura da sociedade. A faceta com o foco na sociedade, por sua vez, é dividida em duas teses: a fraca e a forte da não neutralidade. A primeira postula a ideia de que o conhecimento científico-tecnológico internaliza as principais características do contexto vivenciado, constituindo-se funcional para sua permanência. A tese forte, além de incorporar a fraca, entende que a CT é construída de maneira funcional para uma determinada sociedade, estando, portanto, disfuncional para outra organização social, que possui objetivos socialmente diferentes.

Como discutimos neste item, há diferentes teóricos que nos ajudam a compreender a questão da não neutralidade da CT. Nesse sentido, e enquanto síntese, resgatamos as dimensões já apresentadas, de Auler (2002). Santos (2012), em um estudo, articulou as dimensões "i" e "iv" por entender que as decisões das atividades científico-tecnológicas geralmente recebem influências internas e externas à prática científica, podendo, dessa maneira, estar articuladas a desejos e interesses de uma dada comunidade de pesquisa, transferindo intencionalidades para o produto científico-tecnológico. Logo, nessa perspectiva, não há respaldos para a percepção de CT como instrumentos neutros de um projeto político. Para colaborar com essas discussões e as proporcionadas neste trabalho, sintetizamos por meio de um esquema as interações interdependentes das dimensões trazidas por Auler (figura 01). Entendemos que a dimensão "i" implica em "iii", ou seja, na atividade científica o direcionamento dado resulta de decisões políticas, logo, o conhecimento produzido não se dá apenas nos fatores epistêmicos. $\mathrm{E}$, a dimensão "ii" implica em "iv", pois o aparato científico-tecnológico apropriado resulta de decisões políticas, logo, incorpora questões valorativas de grupos particulares. Nesse sentido, entendemos que as dimensões "i" e "iii" resultam em "ii" e "iv", já que tanto o processo quanto o produto da atividade científica resultam de decisões políticas, e, portanto, não são neutras, premissa que denominamos de "v". 
Figura 01: Esquema das interações das dimensões da não neutralidade da CT de Auler (2002).

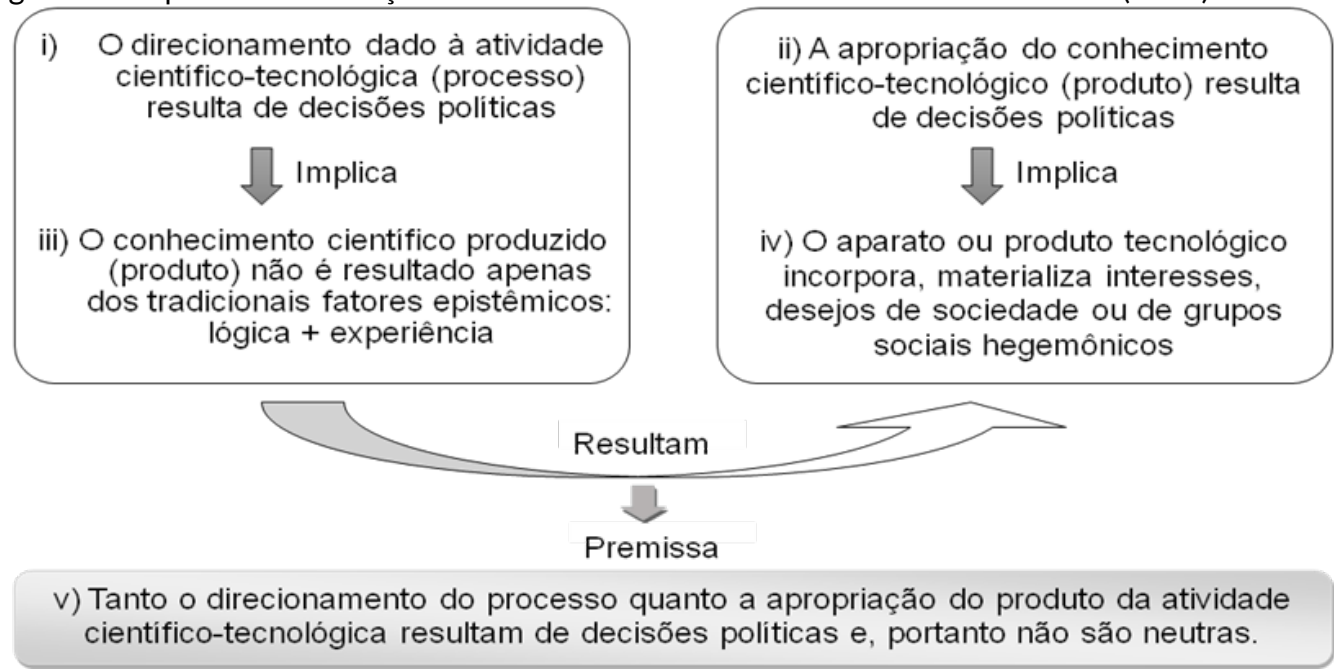

Fonte: produção própria

Retomando o caso do DDT, denunciados por Carson, podemos fazer o exercício de articulação com as dimensões da não neutralidade da CT propostas em Auler (2002). Nesse caso, apesar de sintetizado desde 1874, o DDT só recebeu atenção quando suas propriedades inseticidas foram evidenciadas, quando passou a ser visto como um "sucesso" para resolver um problema social. Na perspectiva linear de desenvolvimento, o combate a doenças e pragas permitiria a expansão da produção agrícola o que, por sua vez, resolveria o problema social da fome. Porém, sabe-se que o problema da fome não é um problema de falta de alimentos. Portanto, no caso do DDT e suas propriedades inseticidas, o direcionamento dado à atividade científico-tecnológica e sua apropriação não resultaram apenas de decisões estritamente técnico-científicas, mas também políticas. Associado a isso, como contraponto à ideia ingênua de que o produto tecnológico é neutro, problematizamos que o inseticida DDT, assim como outros aparatos, internalizam interesses de alguns grupos sociais.

Sendo assim, destacamos novamente que, em virtude das intencionalidades do desenvolvimento científico-tecnológico, a produção de conhecimento também é marcada por fatores que vão além dos epistêmicos. Nesse sentido, o conhecimento científico produzido é influenciado por questões valorativas exteriores aos constituintes da prática científica, visando responder e produzir demandas específicas já direcionadas na definição da atividade científica. Assim, ambas as perspectivas vão influenciar na maneira como o produto oriundo da atividade científico-tecnológica será utilizado, já que o mesmo foi produzido para um determinado fim, ou seja, meios e fins são dependentes. Além disso, serão as decisões políticas no direcionamento e na apropriação da CT que irão, de alguma maneira, estruturar a forma de vida, resultando, 
por exemplo, no estilo de prática agrícola hegemônica que temos na nossa sociedade.

As discussões e reflexões não se esgotam no que foi abordado, mas contribuem para problematizarmos um tema ainda frágil na educação científica mesmo no contexto da educação CTS, concepção que já era questionada no início do movimento. Diante disso, o próximo item visa dar visibilidade para dimensões da não neutralidade silenciadas em práticas educativas CTS. Essa verbalização contribui também para pensarmos as propostas educativas que se encontram no campo polissêmico CTS, as quais, muitas vezes, acabam silenciando dimensões importantes do movimento.

\section{A não neutralidade da ciência-tecnologia e dimensões silenciadas em práticas educativas}

Em trabalhos anteriores (Rosa, 2014; Rosa \& Auler, 2016) foram realizadas discussões teóricas acerca das dimensões da suposta neutralidade da CT levando em consideração alguns pesquisadores que problematizam essa temática. A partir disso e de uma investigação, foram identificadas algumas formas de silenciamentos/ ausências de dimensões relacionados às concepções ingênuas sobre CT no âmbito de práticas educativas CTS no contexto brasileiro, as quais serão apresentadas a seguir.

O primeiro silenciamento refere-se à concepção de CT que pode estar sinalizando o endosso a uma compreensão próxima do determinismo científico-tecnológico. $O$ determinismo tecnológico está alicerçado na visão de tecnologia autônoma, que se desenvolve por meio de sua própria lógica logo, não é condicionado pela ação humana. A tecnologia é entendida como um fator independente, sendo ela a principal causa da mudança social. E ainda, o progresso é considerado como caminho fixo e inexorável (García, Cerezo \& López, 1996).

Problematizar o determinismo tecnológico é ter como pano de fundo uma concepção de CT que esteja voltada aos problemas e necessidades de uma dada sociedade, através de mecanismos de participação que garantam as suas demandas em agendas de pesquisa (Rosa \& Auler, 2016), ou seja, Herrera (2003) crítico da visão determinista da CT entende que países considerados subdesenvolvidos, como o nosso, não deveriam trilhar o mesmo caminho seguido pelos países ditos desenvolvidos, isso porque "levaria à mesma situação de desigualdade social, ao desperdício no uso de recursos, à deterioração do meio ambiente e à alienação da população" (p. 119).

Uma sociedade que omite a origem, a concepção da $\mathrm{CT}$, bem como os valores existentes em todo o processo, não tem potencial para alterar a dinâmica do desenvolvimento científico-tecnológico, tornando-se, cada vez mais, passiva diante dos rumos da CT, dificultando qualquer definição/decisão referente a políticas públicas para CT. É válido 
ressaltar que, por mais que o silenciamento identificado esteja mais relacionado com a participação e percepção da origem do desenvolvimento científico-tecnológico, outras dimensões de participação foram e são mais verbalizadas em práticas CTS, como é o caso da avaliação dos impactos da CT na sociedade. Essa dimensão é considerada limitada por reduzir a participação ao uso dos produtos da CT (Santos, 2012; Rosa, 2014; Santos, 2016; Rosa \& Auler, 2016). O bom destino na apropriação é entendido por Dagnino (2003) como uma aceitação da sociedade aos impactos oriundos do desenvolvimento científico-tecnológico, ou seja, a ação da sociedade está reduzida em tirar o melhor proveito dele. Destacamos que problematizar a participação na dimensão "pós-produção" é necessária, mas limitante. É preciso verbalizar a barreira posta por ela, de apenas receber/aceitar o produto da CT, para uma dimensão de uma maior participação no direcionamento da atividade científico-tecnológica, algo que pode ser iniciada com a verbalização desse primeiro silenciamento.

O segundo silenciamento que deve ser verbalizado em práticas CTS está centrado na discussão de dimensões de outras naturezas, além da científico-tecnológica, em processos decisórios. Este está relacionado com a ideia de que as decisões voltadas ao campo da CT são restritas aos especialistas, sendo estes os únicos atores capazes de solucionar os problemas, inclusive os sociais, de uma maneira eficiente e ideologicamente neutra (Rosa \& Auler, 2016). Este modelo de gestão tecnocrática, dimensão da suposta neutralidade, inibe processos de participação social, pois coloca o campo científico-tecnológico e seus especialistas, tomados ideologicamente como neutros, como suficientes e necessários para o enfrentamento de problemas vivenciados pela humanidade.

Uma das verbalizações necessárias para o enfrentamento deste silenciamento está no fato de que em temas que abordam questões sociocientíficas, a dimensão técnica, do especialista, vem acompanhada e influenciada por dimensões de outras naturezas, como econômica, política e ambiental, as quais são influenciadas, muitas vezes, por interesses próprios ou de uma dada comunidade. Questionar as decisões tecnocráticas parece colocar em segundo plano o conhecimento científico-tecnológico. No entanto, o que se questiona não é a sua importância e relevância e sim, no fato de que nas condições da participação tecnocrática, as decisões de outras naturezas, que acompanham processos técnicos, são tomadas supostamente por uma única voz, a do especialista tido como neutro.

É importante questionar também a ideia de progresso da humanidade, da crença de que o presente é melhor que o passado, e que o futuro será ainda melhor devido exclusivamente ao desenvolvimento da CT, mito denominado de salvacionista e redentora da CT (Auler, 2002). Problematizando essa construção histórica, tem-se a terceira verbalização necessária, que está relacionada com os valores internalizados no produto científico-tecnológico. Essa construção histórica, considerada parcialmente superada no contexto da educação CTS (Rosa \& Auler, 2016), por não linearizar a 
concepção entre mais CT e mais bem-estar social, revelou-se silenciada em um aspecto fundamental, nas relações sociais em que CT são concebidas e utilizadas, ou seja, ignoram-se os valores e interesses no processo, produto e apropriação.

A não linearidade presente entre mais CT e mais bem-estar social não decorre apenas do uso dado à CT - bom e mau uso -, mas também "do fato de que o produto científicotecnológico incorpora, internaliza, materializa valores, interesses daqueles atores sociais que conceberam esse produto" (Rosa \& Auler, 2016, p. 222). A verbalização necessária está no fato de que as consequências positivas e negativas, potencialização ou não para qualidade de vida já estariam incorporados/previstas, ou de alguma maneira condicionada, independente do uso, considerando os valores e interesses daqueles que o conceberam.

Lacey (2010) ajuda-nos a compreender as verbalizações dos valores internalizados no campo da CT. Para essa reflexão, ele utiliza dois exemplos de práticas na agricultura, uma associada à biotecnologia e a outra voltada à agricultura local/tradicional. Para ele, cada produção internaliza valores. De um lado, respectivamente, têm-se as práticas mercadológicas, de lucro e mais individuais, voltadas a interesses privados. De outro, valores de sustentabilidade ambiental, solidariedade e preservação da biodiversidade. Apenas um bom uso/boa apropriação, não garantirá uma qualidade social desejável e redução de impactos socioambientais, isso porque as consequências de cada produção são possivelmente previsíveis quando considerados os valores internalizados na sua produção (Rosa \& Auler, 2016).

\section{A não neutralidade da ciência-tecnologia e dimensões verbalizadas em práticas educativas}

Dando continuidade às discussões, neste item são descritas práticas educativas que verbalizam os silenciamentos anteriormente discutidos e que estão associadas à suposta neutralidade científico-tecnológica. Essas práticas foram selecionadas a partir de um levantamento da produção da área de ensino de ciências, em específico, de artigos publicados nos seguintes periódicos: Alexandria - Revista de Educação em Ciência e Tecnologia; Ciência \& Educação, Ciência \& Ensino; Ensaio - Pesquisa em Educação em Ciências; Investigações em Ensino de Ciências; Revista Brasileira de Pesquisa em Educação em Ciências. Os artigos encontrados foram analisados seguindo a metodologia da Análise Textual Discursiva (Moraes \& Galiazzi, 2011).

Neste trabalho, optamos por apresentar a análise de somente um exemplar para cada verbalização. Considerando que a intenção do artigo é verbalizar dimensões da suposta neutralidade científico-tecnológica visando perspectivas que contribuam para a constituição de uma cultura de participação em temas sociais de $\mathrm{CT}$, entendemos que 
essa estratégia é a mais adequada por permitir discutirmos com maior profundidade as verbalizações, suas potencialidade e limitações.

A prática educativa descrita por Araújo e Formenton (2012) possibilitou verbalizar questões referentes ao determinismo tecnológico, bem como ampliar a percepção da participação apenas no pós-produção. A verbalização proporcionada pelos autores esteve presente tanto nas discussões teóricas quanto na prática desenvolvida. Nesse sentido, nas reflexões teóricas, os autores defendem, fundamentados em Auler (2003), a participação de mais atores sociais nos processos de decisão em CT, visto que a sociedade, de maneira geral, tem o direito de se envolver nas definições do seu destino. Além disso, questionam o atual direcionamento da CT, visto que está orientado, cada vez mais, para investigações que tem em sua lógica a maximização do lucro, problematizando a presença de valores na concepção do desenvolvimento científico-tecnológico. Valores estes que, em linhas gerais, privilegiam interesses de grupos específicos da sociedade e não demandas reais vivenciados pelo contexto latino-americano, seguindo o defendido pelo PLACTS.

Varsavsky (1976), representante do PLACTS, apontava já na década de setenta que a ciência, no mundo de hoje, é ideológica, sendo que em geral "cada tipo de sociedade exige um estilo de ciência próprio, diferente pelo seu conteúdo, seus problemas prioritários, seus métodos de pesquisa e seus critérios práticos de verdade, assim como pelas características sociológicas do grupo de pesquisadores" (p. 7). E ainda, para ele a autonomia científica encontra-se justamente na proposição de um projeto nacional próprio, não oriundo, não copiado, de nenhum modelo vigente, pois, ao "copiar a ciência e tecnologia de outro país - se o desenvolvimento científico for colocado em termos de 'fechar a brecha' - se estará introduzindo, de contrabando, o essencial de seu estilo de vida" (p. 7). Diante disso, entendemos que práticas que verbalizam o direcionamento da CT incluindo demandas contextuais e participação ampla na concepção/origem da CT estão articuladas, mesmo que implicitamente e de maneira ainda limitada, nos pressupostos do PLACTS, como é o caso, no nosso entender, da abordagem de Araújo e Formenton (2012).

A prática citada esteve fundamentada na abordagem temática articulada aos pressupostos do movimento CTS e tinha como objetivo problematizar fontes de energia automotiva, tendo como intuito discutir diferentes fontes energéticas analisando as implicações socioambientais. Assim, as aulas estiveram relacionadas, de acordo com os autores, com discussões voltadas para uma perspectiva de CT não neutras, problematizando, dentre outros aspectos, o mito do progresso científico, do salvacionismo da CT (Auler \& Delizoicov, 2001) e, de uma política científico-tecnológica (PCT) orientada para a redução das desigualdades sociais, humanização do trabalho e superação de impactos gerados pela tecnologia convencional (Dagnino, 2007). O conhecimento produzido e construído ao longo das aulas proporcionaram argumentos referentes ao "consumo, produção de alimentos, emprego, saúde pública, derretimento 
de geleiras, desmatamento de florestas, aquecimento global, contaminações e outras questões sócio-ambientais relevantes" (p.11). Assim, segundo os autores, as atividades contribuíram para ampliar as concepções dos estudantes, como, por exemplo, na verbalização de que a

[...] sociedade deve influenciar nos rumos da pesquisa e desenvolvimento científico e tecnológico, podendo orientar e sinalizar caminhos mais adequados para os mesmos, considerando não apenas suas necessidades imediatas, mas também implicações e impactos sócio-ambientais relacionados (p. 46).

Ainda, para os autores, a participação social nos rumos da CT deve partir de um "desejado e complexo processo que valoriza o diálogo para esclarecimentos das alternativas hoje existentes, envolvendo diferentes saberes e esclarecendo algumas relações de poder envolvidas nesses possíveis caminhos" (p. 46). Articulado aos pressupostos do PLACTS, Araújo e Formenton (2012) destacam que as práticas CTS possibilitaram ampliar as visões dos estudantes diante de discussões que problematizaram a PCT, no sentido que vivemos em lugar que precisar ser cuidado por todos, e que as influências das decisões técnico-científicas e políticas, que são tomadas em outros países com lógica organizacional pautada por valores socioeconômicos insustentáveis, como o consumismo exacerbado e a obsolescência programada, podem impactar diretamente a nossa sociedade.

Apesar dos aspectos promissores desenvolvidos na prática citada, os autores descrevem algumas limitações apontadas pelos estudantes que prejudicaram o aprofundamento da participação social voltado para a compreensão da tecnologia como um processo sociotécnico. Dentre as possibilidades de aprimoramento apontado por Araújo e Formenton (2012) estão as discussões voltadas para a proposta da adequação sócio-técnica (AST), conforme descrito nos trabalhos de Renato Dagnino. Nesta, o desenvolvimento científico-tecnológico é visto como uma construção de grupos sociais e diálogos de saberes logo, decisões políticas e que deve atender demandas não apenas do campo técnico-científico, mas também de diferentes aspectos valorativos, como social, econômico, ambiental, entre outros. Essa perspectiva contribui ainda mais para verbalizações que alimentam concepções ingênuas e deterministas da CT, sinalizando possíveis reorientações e encaminhamentos para trabalhos futuros.

Como exemplar de verbalização do segundo silenciamento, ressaltamos o trabalho descrito por Fabri e Silveira (2013), no qual há um destaque para a importância de se trabalhar com os estudantes perspectivas que discutem dimensões de que os cientistas/ técnicos não possuem verdades absolutas e que outros campos de conhecimentos são necessários, sinalizando horizontes importantes para a educação CTS.

Como discutido, a defesa por processos decisórios tecnocráticos e conhecimentos unicamente técnico-científicos fragiliza processos democráticos em CT, e, portanto, a constituição da participação social nos rumos da CT. Ao problematizar esta 
concepção temos como propósito discutir a suposta ideia de que a dimensão técnica, do especialista, é condição necessária e suficiente na resolução de problemas sociais envolvendo CT. Concepção esta associada às discussões de Japiassu (1975) quanto ao cientificismo, que segundo ele é um alicerce e ideologia da tecnocracia. Neste sentido, para ele o cientificismo, transformado em mito, fundamenta-se em três pressupostos, no qual no nosso entender caso silenciados inviabilizam qualquer processo ampliado de participação social. Assim, esses pressupostos são descritos como: a ciência como único saber racional e objetivo logo, "o melhor dos saberes"; a ciência é o único conhecimento capaz de resolver todos os problemas teóricos e práticos; e cabe ao cientista o papel legítimo e desejável de confiança quanto aos cuidados e direção de todos os problemas humanos (p. 83). E ainda, a ciência não fornece apenas a verdade objetiva e racional, mas também o verdadeiro conhecimento da realidade, da natureza.

Visando exemplificar verbalizações sobre essas discussões, a prática educativa descrita por Fabri e Silveira (2013), as quais propuseram um trabalho interdisciplinar de ciência, tiveram como objetivo construir conhecimentos no qual os estudantes pudessem desenvolver atitudes conscientes e responsáveis sobre $\mathrm{CT}$, tendo como foco a problemática referente a artefatos tecnológicos que norteiam o dia a dia dos estudantes. As atividades, dentre outras, estiveram articuladas a visita a uma cooperativa de reciclagem, entrevista com um cientista, confecção de folders e uma Feira Tecnológica envolvendo a comunidade escolar e local. Enquanto pressupostos teóricos da prática, destacamos nos aspectos trazidos pelas autoras, a importância de utilizar os conhecimentos vivenciados pelos estudantes, dentre eles os saberes populares, visto que a escola, muitas vezes, os ignora privilegiando o conhecimento científico (Chassot, 2004); uma educação voltada para a autonomia no pensar e no agir, em especial, nos temas sociais de CT; e, articular diferentes aspectos valorativos ao desenvolvimento científico-tecnológico.

Enquanto análise da prática, destacamos as concepções iniciais dos estudantes, para os quais, segundo as autoras, os cientistas são especialistas que produzem benfeitorias para a sociedade. Não há menção, neste momento inicial, sobre possíveis implicações sociais do desenvolvimento científico e ainda, não há questionamentos sobre a primazia da ciência. Diante disso, as autoras destacam a importância de problematizar essa concepção, pois a mesma alimenta a ideia do mito da neutralidade referente ao papel dado ao cientista e o conhecimento produzido por ele.

Neste sentido, as atividades seguintes implementadas por uma das autoras tiveram como propósito a desmistificação dessas concepções possibilitando refletir sobre os "fatores externos que envolvem uma pesquisa científica, que ela não é neutra, que é necessário estarmos atentos e que temos que aprender a questionar a sua supremacia e a tomar decisões conscientes e responsáveis em relação à Ciência" (p. 88). E ainda, referente à atividade voltada para o questionamento sobre "o que fariam se fossem cientistas", Fabri e Silveira (2013, p. 88) destacam que, 
[...] assim como eles (os alunos) fizeram propostas que os beneficiaria, se preocupando apenas com eles próprios, os cientistas também podem estar criando coisas que beneficiem somente a si mesmos, ou a interesses de outros, e que nem sempre é para o bem da humanidade, pois as decisões variam de acordo com a perspectiva de cada um, dos interesses envolvidos, sejam eles pessoais, sociais, econômicos e/ou políticos.

Nas discussões acima foram evidenciados aspectos que questionam influências valorativas nos processos decisórios dos especialistas, o que possibilita questionar concepções que alimentam a neutralidade das decisões tecnocráticas. O potencial revelado nesta prática educativa está, dentre outros aspectos, no fato de que as autoras não silenciaram sobre as concepções alimentadas pelos estudantes, referente ao mito tecnocrático, pelo contrário verbalizaram e problematizaram. Aspecto este essencial na busca pelos pressupostos da educação CTS.

Outro destaque desta prática está relacionado com o diálogo realizado com outros atores sociais, que não os cientistas, sobre artefatos tecnológicos, em especial sobre o lixo tecnológico. O diálogo realizado com esses atores sociais tiveram como embasamento o conhecimento deles referente a problemática e de que maneira atuavam sobre ela. Essa prática foi realizada em uma cooperativa de reciclagem que os estudantes visitaram e tiveram a oportunidade de dialogar com os trabalhadores. Os debates, reflexões, visitas e estudos proporcionaram desenvolver conhecimentos sobre artefatos tecnológicos para além do conhecimento científico e dos especialistas técnicos. A visita a cooperativa e o diálogo com os seus trabalhadores contribuíram para a explicações sobre o seu funcionamento, aparatos usados, pessoas envolvidas no trabalho, formas de geração de renda entre as família, dinâmica do trabalho, ações realizadas pela cidade ou o que poderiam ser feitas em prol da reciclagem tecnológica ou seja, outros conhecimentos, outros atores sociais e outras formas de lidar com um problema social. Esses aspectos são de extrema importância visto que vivenciamos uma dinâmica articulada com avanços cada vez mais rápidos dos artefatos tecnológicos, muito estimulado pelo consumismo midiático. E é nesta perspectiva que destacamos, a nosso ver, uma possível limitação da prática desenvolvida. Apesar de verbalizar aspectos voltados para outros conhecimentos e atores sociais, bem como questões valorativas nas decisões técnicas, a prática não avançou sobre as discussões da produção do lixo tecnológico, que está relacionado com o desenvolvimento, concepção/origem da CT, permanecendo apenas nas discussões de conscientização do descarte do lixo comum e tecnológico que é importante, no entanto, fica restrito às discussões de participação social voltada apenas ao pós-produção, conforme discutidos anteriormente.

Referente à verbalização dos valores internalizados no produto científico-tecnológico apresentamos o exemplo da prática educativa de Zuin e Freitas (2007), já que os mesmos ressaltam que foi possível problematizar não apenas aspectos positivos e negativos da CT, mas também os interesses associados e os segmentos sociais que 
sairiam beneficiados pelo desenvolvimento. A prática descrita pelos autores esteve fundamentada por um tema sociocientífico voltado para a transposição das águas do rio São Francisco. A perspectiva teórica que respaldou a prática estava articulada aos propósitos de um tema CTS controverso, o qual tem como principal fundamento a consideração de aspectos valorativos, da ética e da moral nos temas sociais que envolvem CT.

O tema trabalhado por ser considerado de cunho social, já que impacta diretamente a sociedade, é visto sobre diferentes aspectos valorativos e envolve a participação de diversos atores sociais. Segundo Zuin e Freitas (2007) há àqueles atores que estão preocupados com a segurança hídrica, com a geração de emprego, com a diminuição do êxodo rural, com os riscos socioambientais, com a situação econômica e técnica do empreendimento, e, ainda, com a agricultura. Preocupação articulada com questões valorativas que atingem cada grupo social refletindo nas suas concepções para possível desenvolvimento da CT. Aspectos esses no qual os estudantes, na execução de uma das atividades que estava voltada para a produção de textos sobre o tema, consideraram "além de dados científicos e informações técnicas, também as dimensões associadas à ética e ao juízo de valores provenientes de diferentes atores sociais favoráveis ou não à interligação da bacia do rio São Francisco às outras bacias do nordeste" (p. 05). Perspectiva esta, a nosso ver, muito importante para os pressupostos da educação CTS, pois verbalizaram e se preocuparam em evidenciar aspectos valorativos internalizados no desenvolvimento científico-tecnológico. Essa atividade que evidenciou na maioria dos estudantes, um posicionamento contrário à realização do empreendimento esteve associada ao questionamento do modelo de desenvolvimento adotado pelos proponentes da obra, tanto do ponto de vista econômico, quanto social e ambiental, visto que apresentava divergências de concepções quando comparado a outros atores sociais, especialistas e não especialistas.

Outro aspecto relevante para a verbalização dos valores associados à concepção da proposição do tema esteve evidenciado no material produzido pelos estudantes, o qual foi problematizado por um grupo: "quem serão os verdadeiros beneficiados por essa transposição do rio São Francisco? A quem interessa essa transposição?" (p. 06). Estes questionamentos verbalizaram, de alguma maneira, os silenciamentos apontados sobre os interesses que estão por trás do desenvolvimento da CT. Essa perspectiva, de extrema relevância para a superação, de fato, do mito salvacionista é coerente com a proposição de Gómez (1997), destacado por Auler (2002) quando destaca que o avanço técnico-científico, como na execução do projeto descrito, é uma atividade humana impressa pela sociedade ou por parte dela. Assim, se há um avanço em algumas áreas e não outras, isso está articulado aos diversos valores presentes e também aos incentivos e recompensas que podem se proporcionados pois, "o avanço tecnológico não opera por si mesmo" (p. 116). Enfim, destaca-se a importância da verbalização dos aspectos valorativos na concepção, execução e desenvolvimento da $\mathrm{CT}$, visto que esses, caso não questionados ou considerados por um conjunto amplo da 
sociedade, podem conferir características que fragilizam, podendo até comprometer, um desenvolvimento científico-tecnológico que contribua para a solução de demandas sociais e contextuais e, portanto, para efetivamente mais qualidade de vida.

\section{Encaminhamentos Finais}

O movimento CTS defende, dentre seus propósitos centrais, a constituição de processos democráticos em CT, aspecto, no nosso entender, possível de ser constituído caso não haja silenciamentos e endosso a concepções ingênuas sobre CT. Dessa maneira e em busca dessa consolidação, que pode ser refletida e desenvolvida em práticas educativas CTS, ressaltamos a importância de verbalizar aspectos essenciais que, caso silenciados, alimentam a suposta neutralidade da CT e, portanto, enfraquecem a busca por processos participativos e da superação dessas concepções ingênuas. Esses silenciamentos estão associados à origem, concepção e direcionamento da $\mathrm{CT}$; aos conhecimentos mobilizados para a resolução de problemas sociais; e, às questões valorativas internalizadas na $\mathrm{CT}$, a busca por uma cultura de participação e formação de cidadãos críticos (Rosa, 2014; Rosa \& Auler, 2016).

Neste sentido, este trabalho teve como preocupação central aprofundar as reflexões sobre esses silenciamentos e sobre a verbalização de dimensões da suposta neutralidade científico-tecnológica, visando perspectivas que contribuam para a constituição de uma cultura de participação em temas sociais de CT. Para isso, partimos de trabalhos já realizados (Rosa, 2014; Rosa \& Auler, 2016) e, além de uma discussão sobre a suposta neutralidade da CT e silenciamentos associados a ela, apresentamos, por meio da análise da produção da área de ensino de ciências, sinalizações de verbalização desses silenciamentos.

Desta análise, destacamos que o desafio, na educação CTS, encontra-se em como efetivar práticas educativas que verbalizem essas dimensões. Neste sentido, entendemos como fundamental a perspectiva teórica de aproximação PLACTS, já discutida, e do educador brasileiro Paulo Freire, pois proporciona um olhar humanizado para as interações CTS. Para Freire (2005) "É a práxis que implica a ação e reflexão dos homens sobre o mundo para transformá-lo" (p. 93). Para que a sociedade construa sua própria história, transformando-a, é essencial a superação da cultura do silêncio, da alienação, da passividade, em busca de uma educação problematizadora e participativa (Freire, 2005). Para ele, alfabetizar é muito mais do que ler palavras, deve propiciar a leitura do mundo, e só assim é possível transformar a consciência ingênua em crítica. A articulação Freire-CTS e PLACTS é essencial, no nosso entender, para as verbalizações dos silenciamentos em práticas educativas. 
Entendemos também que as verbalizações apontadas contribuem no sentido de melhoramento, transformação e viés para reflexão em um repensar das nossas práticas educativas CTS que muitas vezes acabam silenciando concepções essenciais do movimento e na busca pelos seus pressupostos. E é visando ampliar e dar visibilidade para essas questões que o presente trabalho se mostra importante, pois amplia o olhar para futuras práticas educativas verbalizando dimensões que não podem ser negligenciadas na educação CTS. É partir disso que conseguiremos, de alguma maneira, tornar possíveis transformações educacionais e sociais que potencializam a busca de mecanismos ampliados de participação.

\section{Referências}

Aikenhead, G. S. (2003). STS Education: A Rose by Any Other Name. In R. Cross (ed.), A Vision for Science Education: Responding to the Workof Peter J. Fensham (pp 59-75). New York: Routledge.

Araújo, M. S.; \& Formenton, R. (2012) Fontes Alternativas de Energia Automotiva no Ensino Médio Profissionalizante: análise de uma proposta contextualizada de ensino de física em um curso técnico. Alexandria - Revista de Educação em Ciência e Tecnologia, 5(1), 33-61. doi: https://doi.org/10.5007/\%25x.

Auler, D.; \& Delizoicov, D. (2001) Alfabetização Científica-Tecnológica para que? Revista Ensaio - Pesquisa em Educação em Ciências, 1(3), 1-13.

Auler, D. (2003) Alfabetização Científica-Tecnológica: Um Novo "Paradigma"? Revista Ensaio - Pesquisa em Educação em Ciências, 1(5), 69-83.

Auler, D. (2011) Ciência-Tecnologia-Sociedade: dimensões da não-neutralidade. Santa Maria: Projeto de Pesquisa.

Auler, D. (2002) Interações entre Ciência-Tecnologia-Sociedade no Contexto da Formação de Professores de Ciências. (Tese de Doutorado em Educação). Centro de Educação, Universidade Federal de Santa Catarina, Florianópolis.

Carson, R. (2010) Primavera Silenciosa. São Paulo: Gaia.

Cerezo, J. A. L. (1998) Ciência, Tecnología y Sociedad: el estado de la cuestión em 
Europa y Estados Unidos. Revista Iberoamericana de Educación, 18, 125-140.

Chassot, A. A. (2004) A ciência através dos tempos. São Paulo: Moderna.

Dagnino, R. (2010a) As trajetórias dos estudos sobre ciência, tecnologia e sociedade e da política científica e tecnológica na ibero-américa. In R. Dagnino (org.), Estudos Sociais da Ciência e Tecnologia e Política de Ciência e Tecnologia: Alternativas para uma nova América Latina (pp 17-45). Campina Grande: EDUEPB.

Dagnino, R. P. (2010b) Uma estória sobre Ciência e Tecnologia, ou Começando pela extensão universitária... In R. Dagnino (org.), Estudos sociais da ciência tecnologia e política de ciência e tecnologia: abordagens alternativas para uma nova América Latina (pp 293-324). Campina Grande: EDUEPB.

Dagnino, R. P. (2008) Neutralidade da ciência e determinismo tecnológico: um debate sobre a tecnociência. Campinas: Unicamp.

Dagnino, R. (2007) Os Estudos sobre Ciência, Tecnologia e Sociedadee a Abordagem da Análise de Política: Teoria e Prática. Revista Ciência e Ensino. 1(especial), 1-12.

Dias, R. (2008) Um tributo ao pensamento Latino-Americano em Ciência, Tecnologia e Sociedade (PLACTS). Revista Espaço Acadêmico, 90, 1-6.

Fabri, F., \& Silveira, R. M. C. F. (2013) O Ensino de Ciências nos anos iniciais do Ensino Fundamental sob a ótica CTS: uma proposta de trabalho diante dos artefatos tecnológicos que norteiam o cotidiano dos alunos. Investigações em Ensino de Ciências, 18(1), 77-105.

Freire, P. (2005) Pedagogia do oprimido. Rio de Janeiro: Paz e Terra.

Gall Centa, F; \& Muenchen, C. (2016) O Despertar para uma Cultura de Participação no Trabalho com um Tema Gerador. Alexandria - Revista de Educação em Ciência e Tecnologia, 9(1), 263-291. doi: https://doi.org/10.5007/1982-5153.2016v9n1p263

García, M. G., Cerezo, J. A. L., \& López, J. L. L. (1996) Ciencia, Tecnologia Y Sociedad: una introducción al estudio social de la Ciência y la tecnología. Madrid: Tecnos.

Herrera, A. O. (1995) Los determinantes sociales de la política científica en AméricaLatina: Política científica explícita y política científica implícita. Redes, Quilmes, 2(5), 117-131.

Japiassu, H. (1975) O mito da neutralidade científica. Rio de Janeiro: Imago.

Lacey, H. (2010) Valores e atividade científica 2. São Paulo: Associação Filosófica Scientia e Studia/Editora 34. 
Moraes, R.; \& Galiazi, M. C. (2011) Análise Textual Discursiva. Ijuí: Editora Unijuí.

Oliveira, M. B. (2003) Considerações sobre a neutralidade da ciência. Trans/form/ ação, São Paulo, 26(1), 161-172.

Oliveira, M. B. (2008) Neutralidade da ciência, desencantamento do mundo e controle da natureza. ScientiæStudia, São Paulo, 6(1), 97-116.

Pereira, E. M. (2012) Rachel Carson, ciência e coragem. Revista Ciência Hoje. Rio de Janeiro. Disponível na internet: <http://www.cienciahoje.org.br/revista/materia/ id/658/n/rachel_carson,_ciencia_e_coragem>

Rosa, S. E. (2014) Não Neutralidade da Ciência-Tecnologia: Problematizando Silenciamentos em Práticas Educativas Relacionadas à CTS (Dissertação de mestrado em Educação). Universidade Federal de Santa Maria, Santa Maria.

Rosa, S. E., \& Auler, D. (2016) Não Neutralidade da Ciência-Tecnologia: Problematizando Silenciamentos em Práticas Educativas Relacionadas à CTS. Alexandria - Revista de Educação em Ciência e Tecnologia, Florianópolis, 9(2),202-231. doi: https://doi.org/10.5007/1982-5153.2016v9n2p203.

Roso, C. C. (2014) A participação na construção do currículo: práticas educativas vinculadas ao movimento CTS (Dissertação de Mestrado em Educação). Centro de Educação, Universidade Federal de Santa Maria, Santa Maria.

Santos, R. A. A. (2012) Não Neutralidade na Perspectiva Educacional CiênciaTecnologia-Sociedade (Dissertação de Mestrado em Educação). Centro de Educação, Universidade Federal de Santa Maria, Santa Maria.

Santos, R. A. (2016) Busca de uma participação social para além da avaliação de impactos da ciência-tecnologia: sinalizações de práticas educativas (Tese de Doutorado em Educação). Centro de Educação, Universidade Federal de Santa Maria, Santa Maria.

Santos, W. L. P. (2011) Significados da educação científica com enfoque CTS. In W. L. P. Santos, \& D. Auler (org.). CTS e educação científica: desafios,tendências e resultados de pesquisas (pp 21-47). Brasília: Universidade de Brasília.

Strieder, R. (2008) Abordagem CTS e Ensino Médio: Espaços de Articulação (Dissertação de Mestrado em Ensino de Ciências). Instituto de Física, Universidade de São Paulo, São Paulo.

Strieder, R. (2012) Abordagem CTS na Educação Científica no Brasil: Sentidos e Perspectivas. (Tese de Doutorado em Ensino de Ciências). Instituto de Física, Universidade de São Paulo, São Paulo. 
Varsavsky, O. (1976) Por uma política científica nacional. Rio de Janeiro: Paz e Terra. Von Linsingen, I. (2007) Perspectiva educacional CTS: aspectos de um campo em consolidação na América Latina. Ciência \& Ensino, 1(especial), 1 -19.

Zuin, V. G., \& Freitas, D. (2007) A Utilização de Temas Controversos: estudo de caso na formação de licenciandos numa abordagem CTSA. Ciência \& Ensino, 1 (especial), 1-9.

Suiane Ewerling da Rosa é Professora na área de Física Geral/Ensino de Física na Universidade Federal do Oeste da Bahia (UFOB), campus Barreiras e Doutoranda do Programa de Pós Graduação em Educação em Ciências na Universidade de Brasília (UnB). Desenvolve pesquisas na área de Educação em Ciências/Física, com ênfase em Currículo, Ciência-Tecnologia-Sciedade (CTS), Pensamento Latino-Americano em Ciência-Tecnologia-Sociedade (PLACTS), Abordagem Temática, Formação de Professores e Práticas Pedagógicas.

Roseline Beatriz Strieder é Professora do Instituto de Física da Universidade de Brasília (UnB) e orientadora do Programa de Pós Graduação em Educação em Ciências nessa mesma universidade. Desenvolve pesquisas na linha Educação Científica e Cidadania, fundamentadas pelos pressupsotos da Educação Ciência-Tecnologia-Sciedade (CTS) e do educador Paulo Freire. 